Y. H. PARK, H. R. AHN, B. CANTURK, S. I. JEON, S. LEE, H. KANG, * G. A. MOLANDER,*

\title{
One-Pot Preparation of Hydroxyaryl- and (Hydroxyalkyl)aryltrifluoroborates
}

\section{Key words}

halogen-lithium exchange reaction

hydroxyaryltrifluoroborates

(hydroxyalkyl)aryltrifluoroborates

Suzuki-Miyaura cross-coupling

one-pot reaction

Examples:

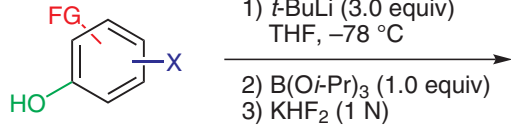<smiles>Oc1ccccc1P(F)(F)(F)F</smiles>

$21 \% \mathrm{X}=\mathrm{Br}$ $77 \% \mathrm{X}=1$<smiles>Oc1cccc(Br)c1</smiles>
$28 \% X=\mathrm{Br}$
$98 \% \mathrm{X}=\mathrm{I}$<smiles>Oc1ccc(Br)cc1</smiles>
$61 \% \mathrm{X}=\mathrm{Br}$ $98 \% X=1$

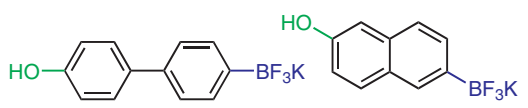
$37 \% X=B r$
$86 \% X=I$

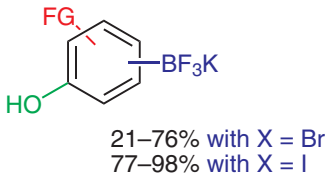

Significance: A simple one-pot synthesis of both potassium hydroxyaryl- and (hydroxyalkyl)aryltrifluoroborates was developed. The respective hydroxyl groups are protected in situ via deprotonation with $t$-BuLi. The hydroxylated trifluoroborates could be successfully subjected to Suzuki-Miyaura cross-coupling.
Comment: This method offers an easy one-pot access to various hydroxylated trifluoroborates. Organotrifluoroborates are often superior to their boronic acid or ester counterparts in SuzukiMiyaura cross-coupling reactions where they are less subject to protodeboronation. Moreover, organotrifluoroborates are stable, crystalline solids that are easy to purify.

SYNFACTS Contributors: Paul Knochel, Tobias Thaler DoI: 10.1055/s-2008-1072781; Reg-No.: P05308SF 